\title{
Intra-domain communication between the N-terminal and DNA-binding domains of the androgen receptor: modulation of androgen response element DNA binding
}

\author{
Jacqueline Brodie and lain J McEwan \\ School of Medical Sciences, College of Life Sciences and Medicine, University of Aberdeen, Foresterhill, Aberdeen AB25 2ZD, Scotland, UK \\ (Requests for offprints should be addressed to I J McEwan; Email iain.mcewan@abdn.ac.uk)
}

\begin{abstract}
The androgen receptor (AR) is a ligand-activated transcription factor that recognises and binds to specific DNA response elements upon activation by the steroids testosterone or dihydrotestosterone. In vitro, two types of response element have been characterised - non-selective elements that bind the androgen, glucocorticoid and progesterone receptors, and androgen receptor-selective sequences. In the present study, the allosteric effects of DNA binding on the receptor amino-terminal domain (NTD) were studied. Binding to both types of DNA response element resulted in changes in the intrinsic fluorescence emission spectrum for four tryptophan residues within the AR-NTD and resulted in a more protease-resistant conformation. In binding experiments, it was observed that the presence of the AR-NTD reduced the affinity of receptor polypeptides for binding to both selective and non-selective DNA elements derived from the probasin, PEM and prostatin $\mathrm{C} 3$ genes respectively, without significantly altering the protein-base pair contacts. Taken together, these results highlight the role of intra-domain communications between the AR-NTD and the DNA binding domain in receptor structure and function.
\end{abstract}

Journal of Molecular Endocrinology (2005) 34, 603-615

\section{Introduction}

The steroid hormones, testosterone and dihydrotestosterone, alter patterns of gene expression in target cells by binding to, and activation of, the intracellular androgen receptor (AR). The AR protein has a modular structure composed of a C-terminal ligand binding domain (LBD) linked to a DNA binding domain (DBD) by a hinge region of 50 amino acids and a large, polymorphic N-terminal domain (NTD), important for transcriptional regulation (reviewed in Gelmann 2002, McEwan 2004). The DBD is a defining feature of the nuclear receptor superfamily and is necessary for specific DNA recognition and binding (reviewed in Zilliacus et al. 1995, Verrijdt et al. 2003, Claessens \& Gewirth 2004). The DBD consists of eight conserved cysteine residues that co-ordinately bind two zinc ions, which are critical for the folding and function of the domain. Nuclear magnetic resonance spectroscopy and X-ray crystallography studies have revealed a common structural folding for the DBD of both steroid and non-steroid receptors, consisting of two $\alpha$-helices arranged in a perpendicular orientation (Zilliacus et al. 1995, Verrijdt et al. 2003, Claessens \& Gewirth 2004). The AR binds DNA as a homodimer with residues in the first zinc module mediating protein-DNA interactions (P-box), and amino acids in the second zinc module involved in protein-protein (dimerisation) interactions (D-box) (Verrijdt et al. 2003, Shaffer et al. 2004). In the case of the $A R$ the amino acids of the C-terminal of the core DBD, termed the 'C-terminal extension', are important for response element recognition and high affinity binding (Schoenmakers et al. 1999).

The AR belongs to a sub-family of steroid receptors that includes the receptors for glucocorticoids (GR), progesterone (PR) and mineralocorticoids (MR). These receptors all have glycine, serine and valine as P-box residues and have been found to bind to similar DNA response elements. Using a DNA binding selection assay, Parker and co-workers proposed the sequence 5'-GGA/TACAnnnTGTTCT-3' as a consensus AR binding site (Roche et al. 1992). This sequence is essentially identical to the consensus glucocorticoid response element (GRE), GGTACAnnnTGTTCT-3' (Zilliacus et al. 1995), and is remarkably similar to the consensus derived from a comparison of over 20 natural AR-binding sequences: 5'-AGA/TACA/Tgca/gT/ AGTTCT-3'. These sequences are palindromic in nature with the receptors binding in a 'head-to-head' configuration, and can be thought of as hormone or steroid response elements (HRE or SRE) to reflect the non-selective nature of binding by this subfamily of steroid receptors. Interestingly, DNA sequences have been identified for a number of genes which selectively 
mediate DNA binding and/or activation by the AR (reviewed in Verrijdt et al. 2003). These sequences have been described as androgen response elements (ARE) and present a modified consensus, 5'-A/GGGT CTnnnA/TGTTCT/C-3', with the main difference being the central two base pairs of the $5^{\prime}$ half-site (underlined) (see McEwan 2004). Comparative analysis of the GR-DBD and AR-DBD binding to non-selective (HRE) and selective (ARE) response elements has highlighted the role of the G-terminal extension in AR selective binding (Schoenmarkers et al. 1999). Further mutational analysis by Claessens and co-workers identified glycine 618 and leucine 625 within the $\mathrm{C}$-terminal extension sequence and threonine 593 within the second $\mathrm{Zn}$ module as crucial residues in the $\mathrm{AR}$ selective binding (numbering for the rat AR; Schoenmaker et al. 2000). However, in addition to half-site recognition there is also evidence from DNA selection studies that nucleotides in the flanking and spacer sequences may also play a role in DNA binding and response element selection (Roche et al. 1992, Nelson et al. 1999). Moreover, investigation of the autoregulation of the AR gene by the receptor has shown that interactions with non-receptor proteins and/or communication between receptor domains are responsible for the AR-specific response (Gonzalez \& Robins 2001, Grad et al. 2001).

The conclusion from the above studies is that multiple mechanisms alone or in combination may be involved in ensuring specificity for AR-dependent gene regulation. In the present study, we have investigated the effects of DNA binding to selective and non-selective response elements on AR-NTD conformation, as well as the possible role of the latter in DNA site recognition and binding. We report that DNA binding to both types of response element led to changes in the conformation of the AR-NTD. The affinity of the AR-DBD was lower for AREs compared with HRE. Significantly, the affinity for both types of response element was further reduced when the AR-NTD was present, although methylation interference experiments revealed no striking differences in protein-DNA contacts. The effect of the AR-NTD was only observed in cis and, taken together with the above findings, strongly support the idea of intra-domain communication between the NTD and DBD of the AR, resulting in changes in protein conformation and protein-DNA interactions.

\section{Materials and methods}

\section{Plasmid constructs}

A fragment of the human androgen receptor from amino acids 529-645 (numbering is human AR with amino repeats of 21 glutamines and 16 glycines) was cloned into the bacterial expression plasmid pGEX-2TK to produce pGEX-AR-DBD. The cDNA encoding the
AR-DBD was amplified by PCR from the plasmid pSVARo using the following primers: forward, 5' GCG CGGGGATCGCGTTTGGAGAGTGCGAGG $3^{\prime}$ and reverse, 5' GCGCGCGGATCGCTCGTCAGTGGGG CTGGTGG 3'. The PGR product was digested with BamHI (sites underlined in the primers) and subcloned into pGEX-2TK (Amersham Biosciences). This PGR product was also subcloned into bacterial expression plasmid encoding the $\mathrm{N}$-terminal domain of the human androgen receptor, pGEX-AR-NTD (amino acids 1-528; plasmid details to be described elsewhere) to give pGEX-AR-NTD-DBD. All plasmids were confirmed by restriction enzyme digests and the ARDBD insert checked by DNA sequencing.

\section{Expression and purification of recombinant proteins}

All plasmids were incorporated into Escherichia coli BLR (DE3) cells. Cultures were grown at $37{ }^{\circ} \mathrm{C}$ until the optical density reached $0 \cdot 6-0 \cdot 8$ and were then induced with $0 \cdot 1-0 \cdot 5 \mathrm{mM}$ isopropyl $\beta$-D-thiogalactoside at $23{ }^{\circ} \mathrm{C}$ for $90 \mathrm{~min}$. Proteins were purified on glutathione Sepharose 4B resin and the GST tag was subsequently cleaved with 25 units thrombin protease (Amersham Biosciences) to release the desired human androgen receptor fragment. All proteins were stored in aliquots in PBS, 15\% glycerol, $2 \mathrm{mM}$ dithiothreitol (DTT), $10 \mu \mathrm{M}$ $\mathrm{ZnCl}_{2}$ and $1 \mathrm{mM}$ benzamidine at $-80^{\circ} \mathrm{C}$. Protein samples were analysed by SDS-PAGE gel electrophoresis and purity was estimated to be greater than $90 \%$. Protein concentration was determined by the method of Bradford using BSA standards and molecular masses of $12870 \mathrm{Da}$ and $70950 \mathrm{Da}$ for the AR-DBD and AR-NTD-DBD polypeptides respectively.

\section{Protein-DNA interactions - electrophoretic mobility shift assays (EMSA)}

Oligonucleotides (Table 1) were end-labelled with ${ }^{33} \mathrm{P}$ $\gamma$-ATP (Amersham Biosciences). Reactions containing 40 pmoles oligonucleotide, 10 pmoles ${ }^{33} \mathrm{P} \gamma$-ATP, $1 \mu \mathrm{l}$ $10 \times$ buffer (Roche), $2 \mu \mathrm{l}$ T4 polynucleotide kinase (Roche) and sterile water to a volume of $10 \mu \mathrm{l}$, were incubated at $37^{\circ} \mathrm{C}$ for $3 \mathrm{~h}$. Labelled DNA was separated from the free label by NAP-5 columns (Amersham Biosciences). Equal amounts (typically 1-5 ng) of upper and lower strand DNA were annealed at $90{ }^{\circ} \mathrm{C}$ for $5 \mathrm{~min}$ and allowed to cool slowly to room temperature. Reactions containing 20000 c.p.m. ${ }^{33} \mathrm{P} \gamma$-ATP-labelled DNA, purified recombinant protein $(0-10000 \mathrm{nM})$, $0.25 \mu \mathrm{g} / \mathrm{ml}$ polyd[I-G] (Roche), $10 \times$ EMSA buffer (100 mM Hepes, pH 7.9, $25 \mathrm{mM} \mathrm{MgCl}_{2}, 0.5 \mathrm{mM}$ EDTA, pH 8, 0.5\% Triton-X, $10 \mathrm{mM}$ DTT and $500 \mathrm{mM} \mathrm{NaCl}$ ), 20\% glycerol and sterile water to give a final volume of $20 \mu \mathrm{l}$, were incubated at room temperature for $20 \mathrm{~min}$ to allow binding to occur 
Table 1 Androgen receptor DNA response elements

Sequence

Binding Site ${ }^{1}$

C3(1)

PbARE2

MMTV

PEM ARE1

IDR17

\author{
AGCTTACATAGTACGtgaTGTTCTCAAGGTCGA \\ TCGAATGTATCATGCactACAAGAGTTCCAGCT \\ ATACAAATAGGTTCTtggAGTACTTTACTAGGC \\ TATGTTTATCCAAGAaCCTCATGAAATGATCCG \\ AAGTTTATGGTTACAaacTGTTCTTAAAACAAG \\ TTCAAATACCAATGTttGACAAGAATTTTGTTC \\ CATCACAGATCTcattcTGTTCCCGGGAC \\ GTAGTGTCTAGAgtaagACAAGGGCCCCTG \\ ATTGCAATGGGAACGGAACATGTTCTGATCCTGTAG \\ TAACGTTACCCTTGCCTTGTACAAGACTAGGACATC
}

${ }^{1} \mathrm{C} 3(1)$ represents the androgen receptor binding site identified within the first intron $(+1359)$ of the C3 subunit of the prostatic binding protein (prostain) (Claessens et al. 1989); PbARE2 is the androgen receptor selective response element identified and characterised in the 5 '-flanking sequence $(-140$ to -117) of the rat probasin gene (Rennie et al. 1993, Claessens et al. 1996); MMTV represents a hormone response element (HRE) derived from the mouse mammary tumour virus long terminal repeat (Parker et al. 1987); ARE1 was identified as an androgen receptor selective response element in the promoter (-85 to -69) of the PEM homeobox transcription factor gene (Barbulescu et al. 2001); IDR17, is an artificial response element selected from a partially-degenerate pool of oligonucleotides, that contains both direct and inverted half-site motifs (Zhou et al. 1997). Response element half-sites are shown in bold type.

between protein and DNA. Samples were run on a $5 \%$ non-denaturing gel and analysed using the Fujifilm FLA-3000 phosphorimager. Binding curves were drawn of percentage retardation (bound DNA/total DNA) against the protein concentration on Microsoft Excel and the concentration corresponding to $50 \%$ saturation was used to calculate the $K_{\mathrm{d}}$ value for each protein.

\section{Competition assay}

Reactions were set up as with EMSA above, except that a constant amount of protein was used $(75 \mathrm{nM}$ AR-DBD and $500 \mathrm{nM}$ AR-NTD-DBD); 200-fold excess unlabelled competitor DNA and $0.5 \mathrm{mg} / \mathrm{ml}$ BSA were also included in the reaction. Reactions were incubated at room temperature for $30 \mathrm{~min}$. Samples were analysed as before.

\section{Antibody studies}

Reactions were set up as with EMSA above, except that a constant amount of protein was used $(500 \mathrm{nM})$. Protein-DNA complexes were allowed to form and $10 \mathrm{mg} / \mathrm{ml}$ antibody (ab3510 (Abcam, Cambridge, UK) recognises the N-terminal 21 amino acids of human AR, AR (441) (Santa Cruz Biotechnology, CA, USA) recognises the N-terminal amino acids 299-315 of the human androgen receptor, G122-77 recognises the DNA binding domain amino acids 486-651 of the human androgen receptor, AR (C19) (Santa Cruz) recognises the $\mathrm{C}$ terminal domain of the human androgen receptor) were added to the reaction and incubated at room temperature for a further $10 \mathrm{~min}$. A control reaction was included that did not contain antibody and the $\mathrm{C}$ terminal domain antibody was used as a non-specific antibody control. Samples were analysed as before.

\section{Fluorescence spectroscopy}

Fluorescence was performed using the Shimadzu 1501 spectorfluorimeter at an excitation wavelength of $278 \mathrm{~nm}$, which measures fluorescence from both tryptophan and tyrosine residues. Samples were prepared containing $25 \mu \mathrm{g} / \mathrm{ml}$ protein with or without DNA at a ratio of $1: 2$, protein:DNA. The volume was increased to $1 \mathrm{ml}$ with buffer $(850 \mu \mathrm{l}$ PBS, $15 \%$ glycerol, $10 \mu \mathrm{M} \mathrm{ZnCl}_{2}$ and $2 \mathrm{mM}$ DTT). The samples containing protein and DNA were incubated for $30 \mathrm{~min}$ at room temperature to allow a protein-DNA complex to be formed. All samples were measured in duplicate in quartz cuvettes. The emission spectra for buffer alone or buffer+DNA binding sites were also measured, after excitation at $278 \mathrm{~nm}$, and subtracted from the appropriate protein spectra.

\section{Proteolysis}

Purified, recombinant A-NTD-DBD was diluted to a final concentration of 40 pmole $/ 20 \mu$ reaction in $10 \times$ EMSA buffer, $20 \%$ glycerol and $0.25 \mu \mathrm{g} / \mathrm{ml}$ polyd[I-G] in the presence or absence of 60 pmoles DNA (C3) 1 ) or 


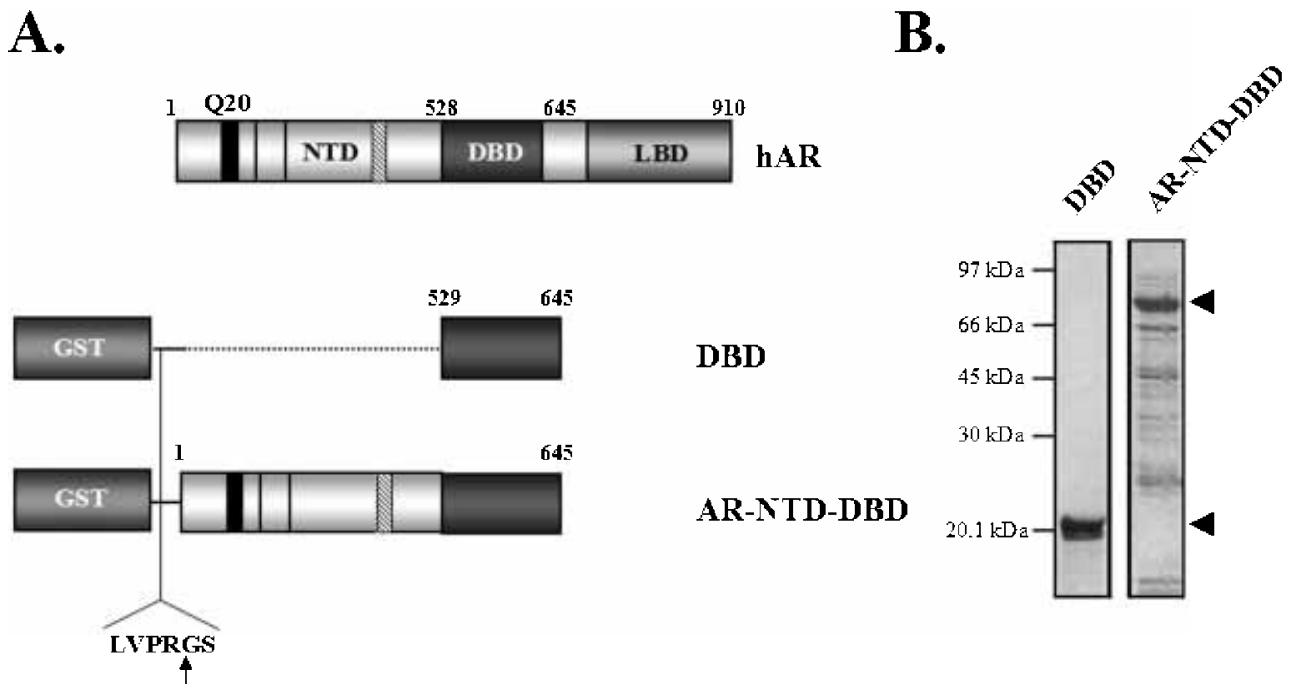

Figure 1 Expression and purification of recombinant receptor polypeptides. (A) Schematic representation of the full-length human androgen receptor, showing the domain organisation. NTD, amino-terminal domain; DBD, DNA-binding domain, LBD, ligand-binding domain. The GST-fusion proteins of the DBD (amino acids 529 to 645) and NTD-DBD (amino acids 1 to 645) and the thrombin cleavage site $(\uparrow)$ are also detailed. (B) Coomassie-stained SDS-polyacrylamide gels showing the isolated AR-DBD and AR-NTD-DBD polypeptides.

PbARE2). Reactions with DNA were incubated for $20 \mathrm{~min}$ at room temperature. Protein or protein-DNA complexes were digested with $2 \mathrm{ng} / \mu \mathrm{l}$ trypsin for 2,6 , 12,18 and $24 \mathrm{~min}$ at room temperature. Reactions were stopped with $2 \times$ SDS-PAGE sample buffer and heating to $75^{\circ} \mathrm{C}$ for $3 \mathrm{~min}$. The samples were separated on a $10 \%$ SDS-PAGE gel, transferred to a polyvinylidene difluoride membrane, probed with a rabbit polyclonal anti-AR antibody which recognised the first 21 amino acids of the androgen receptor $\mathrm{N}$-terminal domain, and visualised by ECL.

\section{Methylation interference}

Methylation interference was carried out as described by Jiricny and Corman (1991). Briefly, oligonucleotides C3(1) or PbARE2 (upper or lower strand) were end-labelled with ${ }^{32} \mathrm{P} \gamma$-ATP (Amersham Biosciences), annealed with the opposite unlabelled strand to give 2 pmoles double stranded DNA and treated with dimethyl sulphate (DMS) $(20 \mu \mathrm{g}$ tRNA, $50 \mathrm{mM}$ sodium cacodylate $\mathrm{pH} 8,1 \mathrm{mM}$ EDTA, $\mathrm{pH}$ 8). The modified DNA $(0 \cdot 1$ pmoles) was then used in EMSA reactions with AR-DBD or AR-NTD-DBD and the bound and free DNA were recovered after electrophoresis and cleaved with piperidine $(0 \cdot 1 \mathrm{M})$ at modified guanosine residues. The cleaved fragments were recovered and resolved on a $12 \%$ polyacrylamide, $7 \mathrm{M}$ urea sequencing gel and detected by autoradiography.

\section{Results}

\section{Purification and DNA binding activity of AR-NTD-DBD polypeptide}

The majority of in vitro studies that have investigated the DNA recognition and binding affinity of the AR have focused on the isolated DBD (see Discussion). In order to examine the possible role of intra-domain communication upon DNA binding and protein conformation, AR-DBD and AR-NTD-DBD recombinant proteins were expressed in E. coli as GST fusion proteins, purified by glutathione-Sepharose affinity chromatography and the GST moiety cleaved by thrombin treatment to yield purified AR-polypeptides (Fig. 1). The binding of the purified AR-DBD and AR-NTD-DBD with both hormone (non-selective) and androgen (selective) DNA response elements was measured using an electrophoretic mobility shift assay (EMSA) and competition with an excess amount of unlabelled DNA response elements. Figure 2 shows the binding of AR-DBD (A) and AR-NTD-DBD (B) to radiolabelled PbARE2, a selective ARE, in the absence or presence of competing DNA. An excess of the non-selective binding site from the C3(1) gene competed most efficiently for the binding of both receptor polypeptides, resulting in $80-90 \%$ inhibition of DNA binding. A comparison of the ratio of binding to DBD/NTD-DBD suggests that competition was greater with AR-NTD-DBD (Fig. 2C). The other binding sites resulted in competition of $40-65 \%$, 


\section{A.}

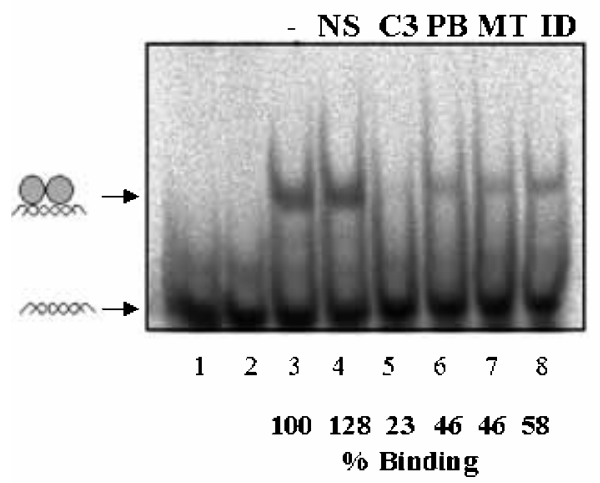

B.

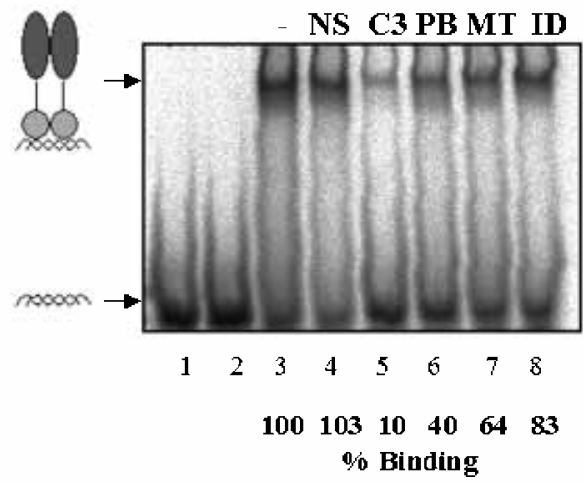

\begin{tabular}{llrrr|} 
C. \\
\cline { 2 - 4 } Comp. & \multicolumn{3}{c}{ \% Binding } & Ratio \\
& DBD & NTD-DBD & DBD/NTD-DBD \\
\hline NS & 109 & 104 & 1.05 \\
C3(1) & 21 & 16 & 1.31 \\
MMTV & 33 & 62 & 0.53 \\
PbARE2 & 42 & 40 & 1.05 \\
ID17 & 43 & 58 & 0.74 \\
\hline
\end{tabular}

Figure 2 DNA binding and competition assay. (A) Binding of the AR-DBD to labelled PbARE2 element in the absence (lane 3 ) or presence of 200-fold molar excess of cold competing non-specific DNA (NS, lane 4), C3(1) element (C3, lane 5), PbARE2 element (PB, lane 6), MMTV HRE2 (MT, lane 7 ) and the ID-17 sequence (ID, lane 8). (B) As in (A) above except binding is with AR-NTD-DBD. (C) Comparison of the average binding observed in the presence of each competitor, and the ratio of binding to AR-DBD and to AR-NTD-DBD is plotted respectively. Representative gels and the quantitation from at least two independent experiments are shown. Free DNA (lanes 1 and 2), schematic representations of the free DNA and protein-DNA complexs are shown to the left of each gel.

MMTV and ID-17 competing less well for AR-NTDDBD binding (Fig. 2C). A DNA sequence lacking a recognised AR binding site failed to compete for the binding (Fig. 2A,B). From these studies and studies with radiolabelled C3(1) (data not shown) we can conclude that, as expected, both AR polypeptides specifically bind to both selective and non-selective response elements and that the efficiency of competition may be affected by the presence of the AR-NTD. Figure 3 shows the effect of AR-specific antibodies on DNA binding by AR-NTDDBD. Addition of an antibody that was reported to recognise the DBD resulted in a supershift of the proteinDNA complexes (Fig. 3, lower panel: DBD). However, this antibody failed to supershift the DBD polypeptide, suggesting the antibody recognizes a sequence(s) within the NTD (data not shown). A similar super shift was observed with a mouse monoclonal antibody against amino acids 299 to 315 (Fig. 3, lower panel: 441). Strikingly, no effect on DNA binding was detected with a polyclonal antibody raised against the first 21 amino acids of the AR-NTD (Fig. 3, lower panel: NTD3510). However, this may simply reflect the inability of this antibody to recognise the native protein. As a negative control an antibody against an epitope in the carboxy-terminal LBD was used (Fig. 3, lower panel: CTD). Similar results were observed with binding to the C3(1) response element (data not shown). From these findings we conclude that sequences within the AF-1 transactivation domain and immediately N-terminal of the DBD are surface exposed and can be recognized by specific antibodies. 


\section{AR-NTD-DBD}
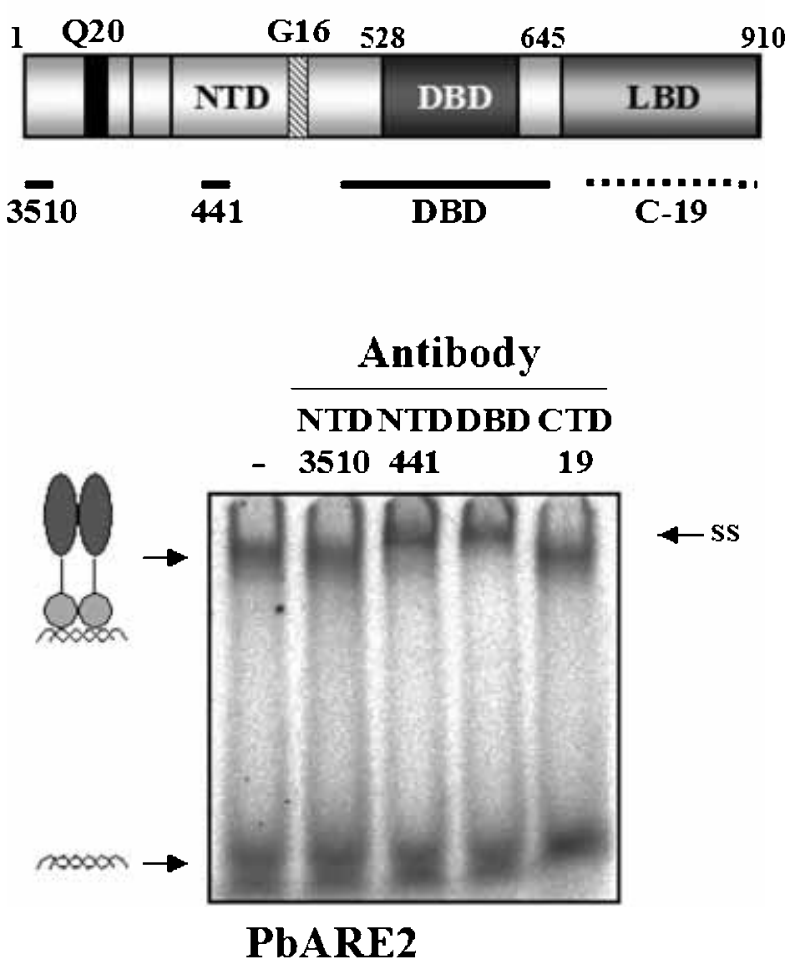

Figure 3 Antibody binding to AR-DNA complexes. (Upper panel) A schematic representation of the AR protein indicating antibody-binding sites (below). (Lower panel) A representative gel-mobility shift assay of the AR-NTD-DBD protein and labelled PbARE2 binding site in the absence (lane 1) or presence of antibodies against the AR-NTD (lanes 2 and 3), DBD (lane 4) and the carboxy-terminal LBD (CTD; lane 5). Schematic representations of the free DNA and protein-DNA complexes are shown to the left of the gel.

\section{AR-NTD conformational changes upon DNA binding}

We have previously reported that a region of the AR-NTD, including the main determinants for transactivation, has little stable secondary structure in aqueous solution (Reid et al. 2002). However, folding of this domain was observed in the presence of structure stabilising solutes and, crucially, upon binding the target protein TFIIF (Reid et al. 2002, Kumar et al. 2004). We were therefore interested to investigate the role of DNA binding on the folding of the AR-NTD and the influence of selective and non-selective DNA sequences.

The steady-state fluorescence emission spectrum for tryptophan has proved a useful means of investigating the folding of the NTD or the AF-1 domain of the glucocorticoid and androgen receptors (see Kumar et al. 2001, Reid et al. 2002, Betney \& McEwan 2003), as well as demonstrating conformational changes in the transcription factor AP1 (Patel et al. 1990) and glucocorticoid receptor (Kumar et al. 1999) upon DNA binding. There are four tryptophan (positions 396, 432, 493 and 517) residues and nineteen tyrosine residues located within the AR-NTD, which allows the intrinsic fluorescence emission spectroscopy of this domain to be measured under different experimental conditions. The emission spectrum after excitation at $278 \mathrm{~nm}$ gives information about protein folding due to the distant dependent energy transfer from tyrosine to tryptophan residues, and information about the local conformation surrounding the tryptophans. To investigate the possible influence of the DBD and DNA binding on the AR-NTD, the fluorescence emission spectrum was measured after excitation at $278 \mathrm{~nm}$ in the absence or presence of specific DNA response elements. Figure 4A shows the steady-state emission spectrum for AR-NTD and AR-NTD-DBD; the $\lambda_{\max }$ for tryptophan was 338 and $337 \mathrm{~nm}$ respectively. In the presence of the AR binding sites from the $\mathrm{C} 3(1)$ or probasin $(\mathrm{Pb})$ genes there is a dramatic quenching of the fluorescence emission for the AR-NTD-DBD and a minor shift in the $\lambda_{\max }$ for tryptophan (Fig. 4B). Similar results were observed after excitation at $295 \mathrm{~nm}$, which activates only tryptophan residues (data not shown). Thus, while the presence of the DBD per se did not significantly alter the conformation of the AR-NTD there was a change in the emission spectrum upon binding to specific DNA response elements. As the four tryptophans and nineteen out of twenty-four tyrosines are present in the AR-NTD, these results suggest that upon DNA binding there is a conformational change in this domain.

Sensitivity to proteolytic digestion has also been used to study protein conformation, as the ability of the protease to cut will depend upon the accessibility of cleavage sites which, in turn, reflect the folding of the polypeptide chain. Partial proteolysis with the enzyme trypsin was also used to investigate possible changes in protein conformation on DNA binding. In the presence of both non-selective and selective DNA response elements there were quantitative and minor qualitative differences in the N-terminal fragments observed. The main effect was the stabilization of the full-length protein from proteolysis, with 40 to 50\% of AR-NTD-DBD remaining in the presence of $\mathrm{C} 3(1)$ and PbARE2 binding sites compared with less than $20 \%$ in the absence of DNA, after 24 min (Fig. 5). Interestingly, at earlier time points there was less protection with the non-selective C3(1) sequence. These results suggest that binding to DNA leads to a conformational change consistent with a more protease-resistant structure within the AR-NTD. Taken together, the results of the above studies suggest that DNA binding results in a conformational change(s) within the AR-NTD, resulting in different regions of the receptor being surface exposed. 


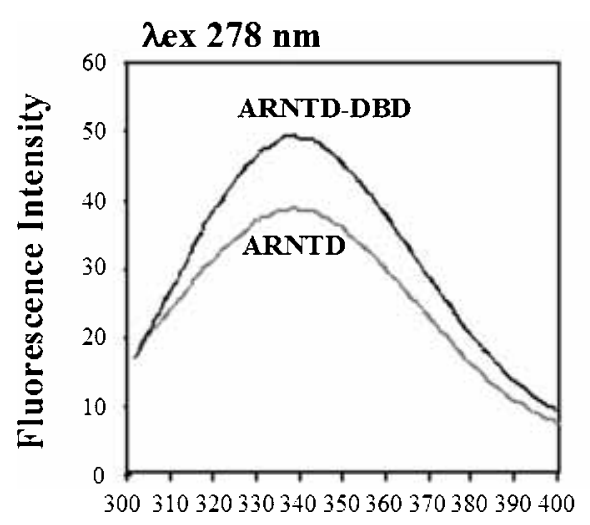

Wavelength (nm)

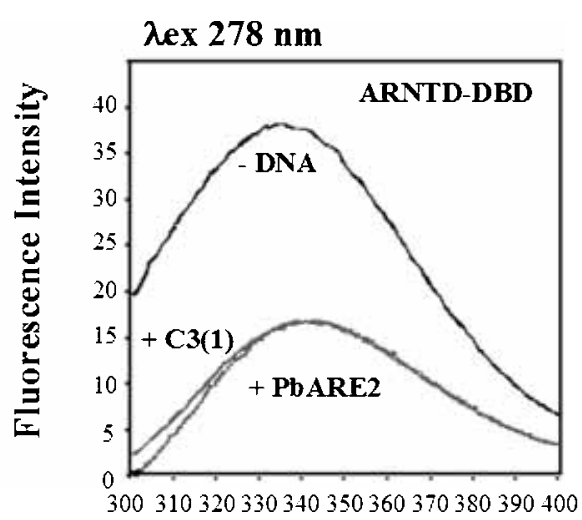

Wavelength (nm)

Figure 4 Fluorescence emission spectra for AR-NTD-DBD. (A) Steady state fluorescence emission spectra for AR-NTD and AR-NTD-DBD after excitation at $278 \mathrm{~nm}$. Spectra were measured in duplicate and the average $\lambda_{\max }$ for tryptophan from two or three independent experiments was $336 \mathrm{~nm}$ for both polypeptides. (B) Steady state emission spectra for AR-NTD-DBD after excitation at $278 \mathrm{~nm}$ in the absence (-DNA) or presence of non-selective (C3(1)) or selective (PbARE2) DNA response elements. Emission spectra were measured in duplicate and the average $\lambda_{\max }$ for tryptophan was $336 \mathrm{~nm}$ and $338 \mathrm{~nm}$ in the absence and presence of DNA respectively. Note: spectra were corrected for buffer and the presence of DNA sequences. $\lambda$ ex =excitation wavelength.

\section{Role of the AR-NTD in DNA recognition and binding affinity}

The above results indicated that DNA binding resulted in a conformational change in the AR-NTD. Previously, it has been reported that the AR-NTD plays a role in DNA binding specificity (Grad et al. 2001). Having established conditions for specific DNA binding, increasing amounts of each protein were titrated against a single concentration of labelled PbARE2 (Fig. 6A,B). From the gel mobility shift experiments the percentage of DNA bound was calculated and plotted against protein concentration (log scale), from which the apparent dissociation constant $K_{\mathrm{d}}$ was calculated (Fig. $6 \mathrm{C}, \mathrm{D})$. Table 2 summarises the apparent binding affinities for both AR-DBD alone and AR-NTD-DBD proteins with the DNA sequences C3(1), PbARE2 and PEM. The binding affinity of the AR-DBD for the AR-selective elements from the probasin and PEM genes was significantly reduced compared with the non-selective C3(1) sequence, with apparent $K_{\mathrm{d}} \mathrm{s}$ of 122 , 382 and $35 \mathrm{nM}$ respectively. Strikingly, we observed that in the presence of the AR-NTD the affinity for all three elements was further decreased, with the most dramatic effects seen with the non-selective C3(1) element, with the apparent $K_{\mathrm{d}}$ increasing from $35 \mathrm{nM}$ to $120 \mathrm{nM}$. The effect of the AR-NTD could result from one monomer inhibiting the binding of the second protein (interdomain) or the NTD acting within each monomer (intra-domain). Thus, to determine if this action required the two domains to be physically linked the effect of the isolated AR-NTD on DNA binding was tested. Figure 7 shows that the inhibitory affect of the AR-NTD is only observed when the NTD is contiguous with the DBD, as the isolated AR-NTD polypeptide had no effect on DNA binding by the AR-DBD alone. Taken together, these results strongly suggest that the AR-NTD can modulate the DNA binding activity of the DBD by reducing the binding affinity for both selective and non-selective DNA response elements.

The reduction in relative binding affinity observed with AR-NTD-DBD may result from altered proteinprotein and/or protein-DNA contacts of the homodimer. We therefore examined the nucleotide contacts made by AR-DBD and AR-NTD-DBD proteins on different response elements by methylation interference foot-printing. Methylating guanine residues in both half sites and on both strands of the DNA duplex disrupted binding of the AR-DBD to the PbARE2 element (Fig. 8A,C). Modifying guanosines out with the 15 base pairs of the binding site had little or no effect on binding. A similar pattern of foot-printing was observed with AR-NTD-DBD (Fig. 8B,G). Analysis of contacts with the C3(1) element also showed symmetrical binding to both half-sites and no differences between the isolated DBD and AR-NTD-DBD (data not shown, summary Figure 8C). However, in contrast with the PbARE2 sequence, methylating guanosine residues $3^{\prime}$ of the core C3(1) response element, on each strand, showed hypersensitivity and enrichment in the bound fraction (Fig. 8C). Taken together, these results indicate that (i) the presence of the AR-NTD does not alter the specific protein-base pair contacts and (ii) contact with flanking residues may be important for the 

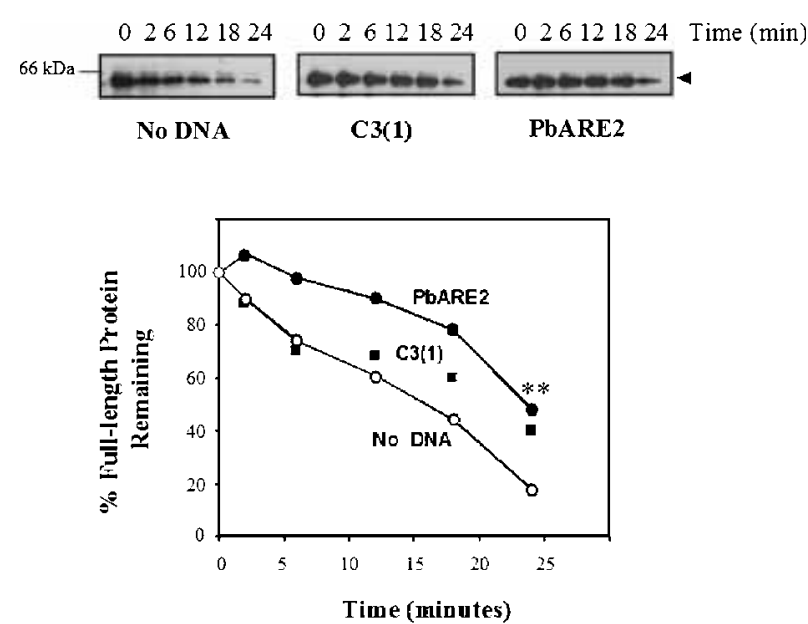

Figure 5 Partial proteolysis of AR-NTD-DBD in the absence or presence of DNA response elements. (Upper panel) Trypsin digestion of the AR-NTD-DBD polypeptide in the absence (No DNA) or presence of the non-selective $(C(3) 1)$ or selective (PbARE2) response element sequences. Detection of the full-length protein was by Western blotting using an antibody (3510) to the first 21 amino acids. (Lower panel) The amount of the full-length androgen receptor polypeptide remaining after $2,6,12,18$ and 24 min was quantified and plotted against time): $O$, represents digestion in the absence of DNA; represents digestion in the presence of PbARE2; represents digestion in the presence of C3(1) DNA sequence. The results are the average of two independent experiments and at 24 min the experimental variations were $33 \%, 8 \%$ and $30 \%$ for No DNA, PbARE2 and C3(1) respectively.

AR binding to the non-selective element from the prostatin $\mathrm{C} 3$ gene.

\section{Discussion}

We have recently reported on the induced folding of the AR-AF-1 transactivation domain in the presence of structure stabilising solutes and the binding partner TFIIF (Reid et al. 2002, Kumar et al. 2004). In the present study, we have extended these findings to include the entire AR-NTD and the influence of DNA binding on protein structure. The binding of the receptor to both non-selective and selective DNA response elements resulted in changes in the endogenous tryptophan fluorescence emissions and a more protease resistant conformation. As the tryptophan residues in the construct studied are located within the AR-NTD, these changes are likely to reflect alterations in the conformation of this region of the protein upon DNA binding. Using antibodies against different regions of the AR-NTD-DBD we found that the AF-1 domain (amino acids 299 to 315) and the region adjacent to the DBD (amino acids 486 to 528) were accessible and therefore likely to be, at least in part, surface exposed.
Furthermore, as the G122-77 antibody did not react with the isolated AR-DBD (amino acids 529 to 645) it suggests that either there is a change in conformation within the DBD when the AR-NTD is present or that the epitope for this antibody lies out with the DBD, in the region of amino acids 486 to 528 (Fig. 3 and data not shown). A more resistant conformation was observed for the AR-NTD-DBD bound to DNA in the present study, although no clear differences were observed between selective and non-selective sequences. Recently, Gerserick et al. (2003) revealed a change in sensitivity to proteolysis that depended on whether the AR was bound to selective or non-selective elements. Complexes formed with nuclear extracts on selective response elements were less accessible to digestion compared with complexes bound to nonselective elements. A similar difference between selective and non-selective DNA response elements was observed in the present study, but only at early time-points. Taken together, these studies support the model of DNA-induced conformational changes within the AR-NTD.

There is increasing evidence, both from studies with nuclear receptors and other transcription factors, for the allosteric effects of DNA binding (reviewed in Lefsti \& Yamomoto 1998). Studies on the DNA binding properties of a number of members of the nuclear receptor superfamily have highlighted an allosteric role of DNA binding on protein conformation. Evidence for intra-domain communication within the oestrogen receptor (ER) comes initially from the use of domain-specific antibodies (Traish \& Pavao 1996), while altered protease sensitivity reveals altered receptor conformation on different oestrogen response elements (ERE) for both ER $\alpha$ and ER $\beta$ (Wood et al. 1998, Klinge et al. 2001, Loven et al. 2001a). In the case of ER $\beta$ bound to different EREs distinct patterns of recruitment of members of the p160 coactivator family were observed (Loven et al. 2001b). With ER $\alpha$ it was clear that coactivator binding stabilised interactions with DNA; however differences in coactivator recruitment were less obvious (Wood et al. 2001). Using circular dichrosim spectroscopy, Greenfield et al. (2001) showed a significant increase in $\alpha$-helix content of the ER $\alpha$ upon binding a palindromic ERE. DNA binding also resulted in an increase in protein stability. Conformational changes were also induced in the non-steroid receptor family member, the thyroid hormone receptor, upon DNA binding, which led to different interactions with the p160 coactivator SRG-1 (Takeshita et al. 1998). Changes in the near UV circular dichroism and fluorescence emission spectra for the NTD-DBD fragment of the GR upon DNA binding also indicated changes in the tertiary structure of the GR-NTD (Kumar et al. 1999). Studies with the A and B forms of the PR indicated that the presence of the DBD stabilized 
A.

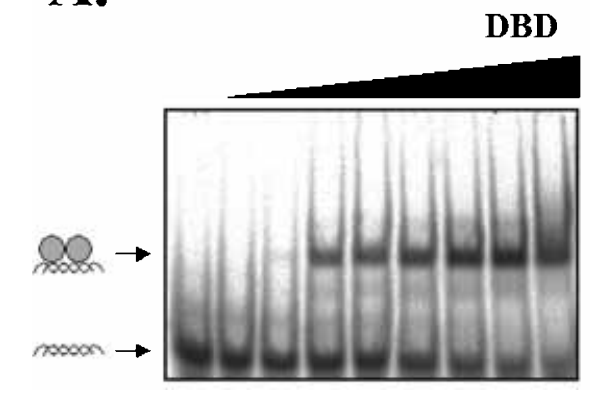

C.

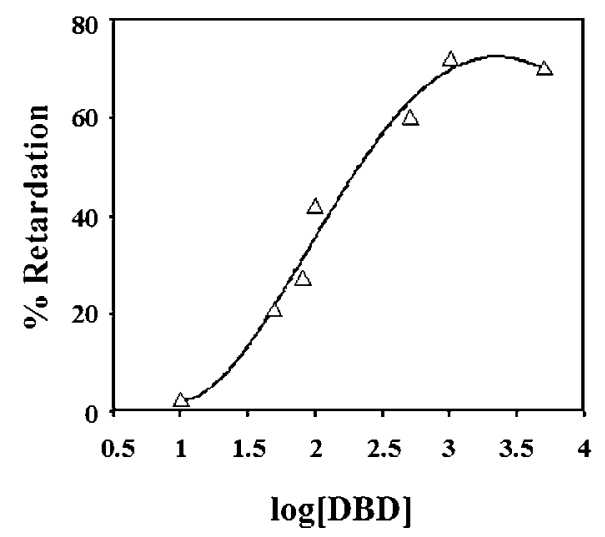

B.

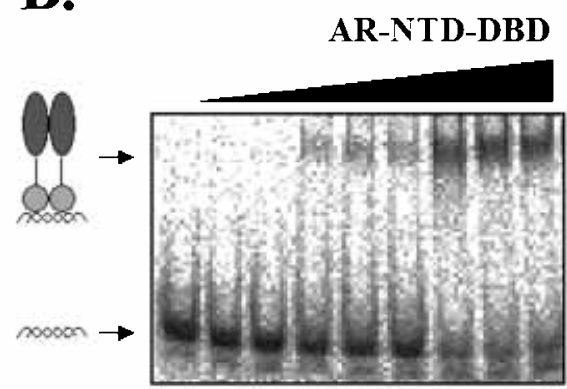

D.

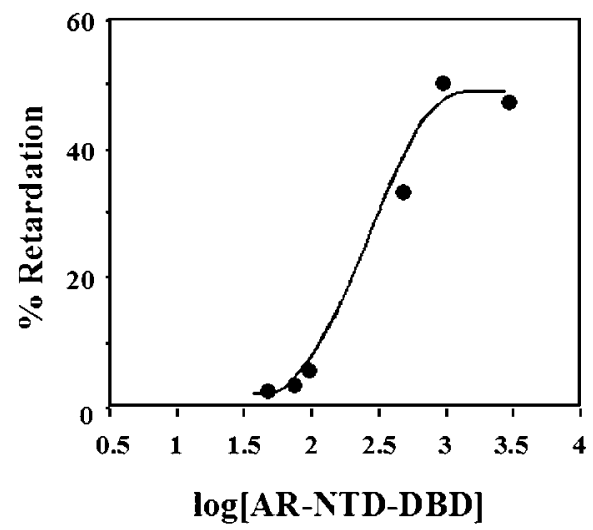

Figure 6 DNA binding affinity of AR-DBD and AR-NTD-DBD polypeptides. (A and B) Representative gel mobility shift assays for the AR-DBD and AR-NTD-DBD proteins bound to the PbARE2 elements. $(C$ and $D)$ The percentage DNA bound was measured and plotted relative to the $\log _{10}$ of protein concentration. From the resulting curves the apparent dissociation constant, $K_{\mathrm{d}}$, was calculated. Schematic representations of the free DNA and protein-DNA complexes are shown to the left of each gel.

the structure of the NTD and hinge regions, but only modest additional effects were observed upon DNA binding (Bain et al. 2000, 2001). It is interesting that although the AR, GR and PR all bind to highly related sequences, the effects of the DBD and/or DNA binding on structure appears to be receptor specific. Taken together, these studies emphasise the role that specific DNA binding can have on the receptor conformation and suggest that this may have an active role in

Table 2 Binding affinities for AR-DBD and AR-NTD-DBD with selective and non-selective DNA response elements

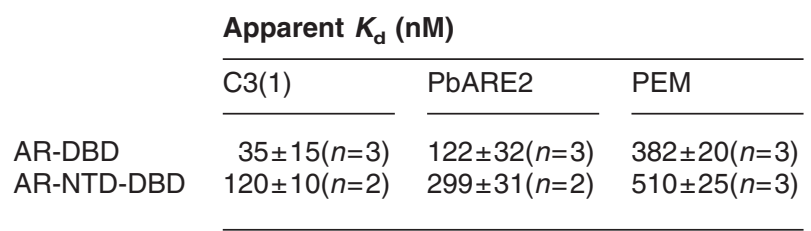

receptor-dependent gene regulation by modulating protein-protein interactions.

A striking difference in binding affinities was observed for the different types of DNA response element used in the present study. The affinity of the AR-DBD for the selective elements from the probasin and PEM genes was 3.5- to 11-fold lower than for the non-selective binding site from the prostatin C3 gene. A survey of the literature reveals that, while the values calculated by different groups can vary widely for different response elements, the trend appears to be for the binding affinity to be greater for non-selective elements such as TAT and C3(1) (see Rudlett \& Miesfeld 1995, Verrijdt et al. 2000, 2002, Haelens et al. 2001). With the AR-NTD present a general reduction in the binding affinity for both types of response element is observed, although the effect appears greater for the non-selective C3(1) element. These data suggest that intra-domain communication between the DBD and the NTD may play a 


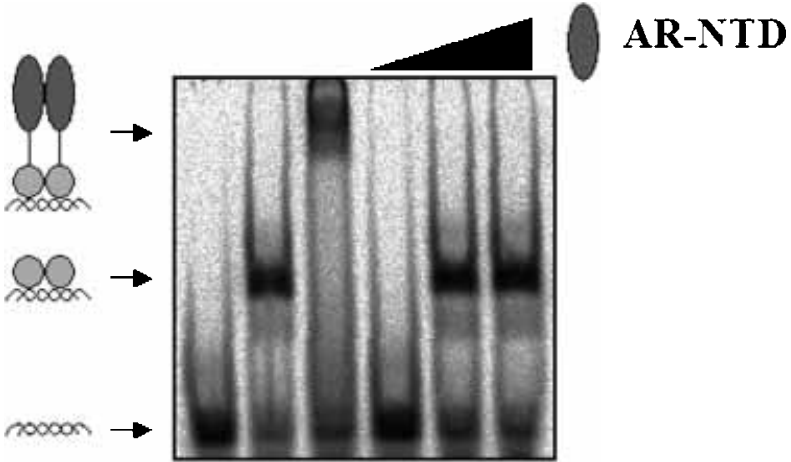

- 10067 - $93102 \quad \%$ Binding

Figure 7 The AR-NTD inhibits DNA-binding in cis. A representative native gel showing the binding of AR-DBD (lane 2) and AR-NTD-DBD (lane 3) to labelled PbARE2 response element. The binding of the AR-NTD-DBD protein is 33\% reduced compared with the molar equal amounts of the DBD alone. The isolated AR-NTD does not interact with DNA (lane 4) and fails to inhibit binding of the AR-DBD at up to a twofold molar excess (lanes 5 and 6). Schematic representations of the free DNA and protein-DNA complexes are shown to the left of the gel.

role in DNA binding selectively. Methylation interference foot-printing revealed symmetrical binding of the AR-DBD to both PbARE2 and C3(1) sequences. Similar contacts for PbARE2 have been observed with DMSprotection studies (Lareyre et al. 2000, Reid et al. 2001). No significant differences were seen when the NTD was present. Interestingly, hypersensitive sites were observed $3^{\prime}$ of the core G3(1) binding site, on both strands and with both receptor proteins. No corresponding contacts were observed with the PbARE2 flanking sequence suggesting a possible difference in binding of the AR homo-dimer to selective and non-selective response elements. Alternatively, these differences may be specific for the flanking sequences of the C3(1) element.

Robins and co-workers have argued that the selective response of the AR depends not only on the DNA architecture of the response sequence but the presence of non-receptor proteins and possible communication between receptor domains (see Gonzalez \& Robins 2001, Grad et al. 2001). The AR-NTD has previously been implicated in the AR-specific response of an internal exonic enhancer sequence, identified within the AR gene. Grad et al. (2001) using AR/GR hybrid receptors showed that the androgen-specific regulation of this regulatory region required the AR-NTD. Whether this is a special case, restricted to autoregulation of the AR gene, or a more general mechanism awaits further analysis of AR selective response elements. The results of the present study support the argument for intra-domain communication between the receptor NTD and DBD, with the former modulating
DNA binding affinity. Interactions between the ARNTD and the AR-LBD are well documented and known to be important for receptor function (see Steketee $e t$ al. 2002, He \& Wilson 2002). Mutagenesis analysis has highlighted a critical role for the first 21 amino acids of the AR-NTD and in particular the motif FqnLL (Steketee et al. 2002, He \& Wilson 2002). Disrupting this motif has a detrimental effect on AR-dependent transactivation. Recently, Wilson and co-workers reported a differential effect of FqnAA mutated receptors on reporter gene transcription, with the activity from the prostate specific antigen (PSA) and probasin enhancer/ promoter sequences being reduced, while the activity from the sex-limited protein (slp) and the MMTV enhancers were unaffected (He et al. 2002). Callerweart et al. (2003) showed that in reporter gene assays with a single response element, transcription from the nonselective response elements from the TAT and C3(1) genes was affected by deletion of the FqnLL motif, but not the selective elements from the slp and secretory component (sc) genes. However, the selective probasin ARE2 element was also affected by the mutation and the apparent selectivity of the mutation was further lost when complex enhancer sequences from the respective genes were used, strongly suggesting that the role of the AR-N/C interactions is context dependent.

An internal deletion in the rat AR, corresponding to residues 47 to 166 in the human AR, resulted in a twoto threefold decrease in the binding to an HRE sequence (Kallio et al. 1994). Similarly, truncation of the AR-NTD to residue 473 also reduced binding to a consensus HRE, while internal deletions near the $\mathrm{C}$-terminus of the NTD resulted in an increase in DNA binding (Gast et al. 1998). Liu et al. (2003) identified an 81 amino acid segment, immediately adjacent to the DBD, which appeared to have an inhibitory action on DNA binding of the AR-DBD to a consensus non-selective response element. The first 20 amino acids of this sequence, immediately adjacent to the DNA, were present in all our constructs, including the isolated AR-DBD (i.e. amino acids 529-549). This would suggest that the inhibitory function lies out with these 20 amino acids or is dependent upon the presence of additional AR-NTD sequences. Interestingly, deletion of the first 187 amino acids from the AR-NTD resulted in a protein with a further two- to threefold reduction in DNA binding affinity on both selective and non-selective response elements. A construct containing only the AR-AF-1 domain (amino acids 142 to 485) fused to the DBD (amino acids 529 to 645 ) exhibited a similar affinity to the AR-NTD-DBD polypeptide (J Brodie and IJ McEwan, unpublished observations). This protein contains less than half of the 81 amino acid sequence described by Liu et al. (2003), lacking residues 486 to 528 and the first 141 amino acids of the NTD. These authors did not report any changes in DNA binding affinity and, 

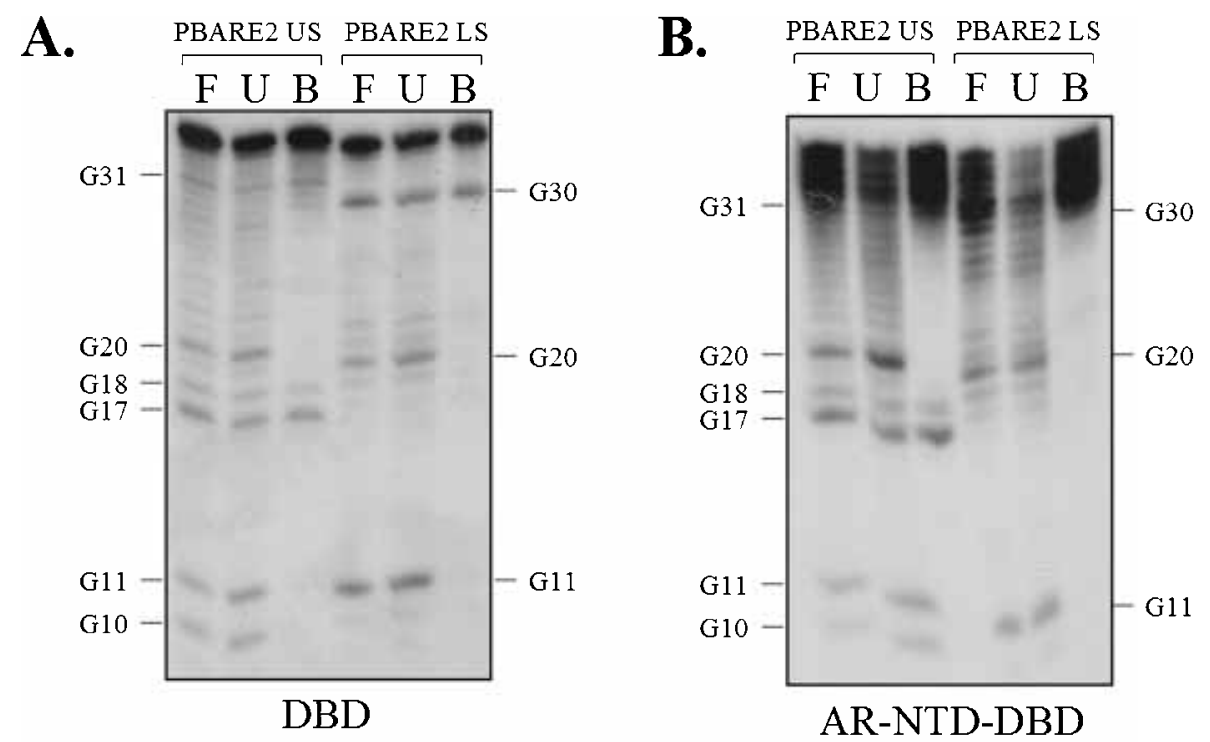

C.

\section{PbARE2}

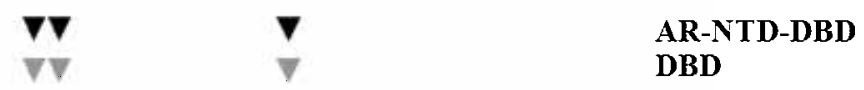

US 5' atacaataGGTTCTtggAGTACTttactaggc $3^{\prime}$

LS tatgtttatCCAAGAaccTCATGAatgatccg

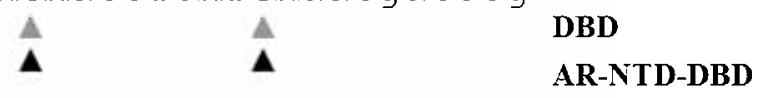

C3(1)

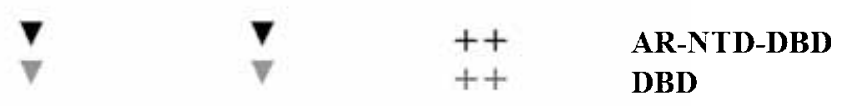

US 5' agcttacatAGTACGtgaTGTTCTcaaggtcga 3'

LS tcgatgtaTCATGCactACAAGAgttccagct

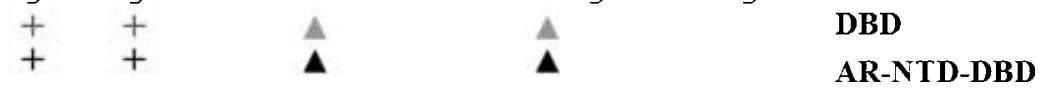

Figure 8 Methylation interference footprinting of AR-DBD and AR-NTD-DBD. (A and B)

Representative sequencing gels showing the protein contacts within the upper (US) and lower (LS) strands of the PbARE2 sequence for AR-DBD and AR-NTD-DBD respectively. $F, U$ and $B$ represent free, unbound and bound DNA respectively. The guanosine residues $(G)$ are numbered from the 5 '-end of the oligonucleotide. (C) Summary diagram showing base contacts for AR-DBD and AR-NTD-DBD with the selective (PbARE2) and non-selective (C3(1)) DNA response elements. Arrowheads represent sites of methylation of G-residues that interfere with protein binding (under-represented in bound fraction), and the plus signs indicate sites of hypersensitivity where methylation leads to increased representation in the bound fraction (for C3(1) sequence only) (solid symbols for AR-NTD-DBD, shaded symbols for AR-DBD). Data is representative of two or three independent experiments.

in contrast to the present study, the observed inhibition appeared to act in trans. Thus, whether the inhibitory region described above and the reduction in DNA binding affinity through intra-domain communication between the AR-NTD and DBD reported here are related awaits further investigation. 
Multiple mechanisms, alone or in combination, are likely to be involved in ensuring specificity for AR-dependent DNA binding and target gene regulation. The AR-NTD is structurally important for receptordependent gene expression mediating multiple proteinprotein interactions (reviewed in McEwan 2004). In the present study we have shown that sequences within the NTD decrease the DNA binding affinity of the receptor for both selective and non-selective response elements, without significantly altering the protein-DNA contacts. Taken together with other studies, these findings emphasise the role of intra-molecular interactions within the AR protein for DNA binding and the subsequent control of target gene expression, and demonstrate that DNA binding involves more than just tethering of the receptor to promoter and enhancer sequences. The full significance of AR binding to different response elements awaits further structural and biochemical analysis.

\section{Acknowledgements}

J B was supported by a BBSRC postgraduate studentship and this work was supported in part by TENOVUS Scotland (Grant G00/2). We are grateful to Dr Albert O Brinkmann (Erasmus University, Rotterdam) for the AR cDNA plasmid pSVARo. The authors declare that there is no conflict of interest that would prejudice the impartiality of this scientific work.

\section{References}

Bain DL, Franden MA, McManaman JL, Takimoto GS \& Horwitz KB 2000 The N-terminal region of the human progesterone A-receptor. Fournal of Biological Chemistry 275 7313-7320.

Bain DL, Franden MA, McManaman JL, Takimoto GS \& Horwitz KB 2001 The N-terminal region of the human progesterone B-receptor. Fournal of Biological Chemistry 276 23825-23831.

Barbulescu K, Geserick C, Schüttke I, Schleuning W-D \& Haendler B 2001 New androgen response elements in the murine PEM promoter mediate selective transactivation. Molecular Endocrinology 15 1803-1816.

Betney R \& McEwan IJ 2003 Role of conserved hydrophobic amino acids in androgen receptor AF-1 function. Fournal of Molecular Endocrinology 31 427-439.

Callewaert L, Verrijdt G, Christiaens V, Haelins A \& Claessens F 2003 Dual function of an amino-terminal amphipatic helix in androgen receptor-mediated transactivation through specific and non-specific response elements. Fournal of Biological Chemistry 278 8212-8218.

Claessens F \& Gewirth DT 2004 DNA recognition by nuclear receptors. In The Nuclear Receptor Superfamily. Essays in Biochemistry, vol 40. Ed IJ McEwan. Colchester: Portland Press.

Claessens F, Celis L, Peeters B, Heyns W, Verhoeven G \& Rombauts W 1989 Functional characterisation of an androgen response element in the first intron of the C3(1) gene of prostatic binding protein. Biochemical and Biophysical Research Communications $164833-840$.

Claessens F, Alen P, Devos A, Peeters B, Verhoeven G \& Rombauts W 1996 The androgen-specific Probasin response element 2 interacts differentially with androgen and glucocorticoid receptors. Fournal of Biological Chemistry 271 19013-19016.

Gast A, Schneikert J \& Cato ACB 1998 N-terminal sequences of the human androgen receptor in DNA binding and transrepressing functions. Fournal of Steroid Biochemistry and Molecular Biology 65 $117-123$.

Gelmann EP 2002 Molecular biology of the androgen receptor fournal of Clinical Oncology 20 3001-3015.

Gerserick C, Meyer H-A, Barbulescu K \& Haendler B 2003 Differential modulation of androgen receptor action by deoxyribonucleic acid response elements. Molecular Endocrinology 17 $1738-1750$

Gonzalez MI \& Robins DM 2001 Oct-1 preferentially interacts with androgen receptor in a DNA-dependent manner that facilitates recruitment of SRC-1. Fournal of Biological Chemistry 276 $6420-6428$

Grad JM, Lyons LS, Robins DM \& Burnstein KL 2001 The androgen receptor (AR) amino-terminus imposes androgen-specific regulation of $\mathrm{AR}$ gene expression via an exonic enhancer. Endocrinology 142 1107-1116.

Greenfield N, Vijayanathan V, Thomas TJ, Gallo MA \& Thomas T 2001 Increase in the stability and helical content of estrogen receptor $\alpha$ in the presence of the estrogen response element: analysis by circular dichroism. Biochemistry $406646-6652$.

Haelens A, Verrijdt G, Callewaert L, Peeters B, Rombauts W \& Claessens F 2001 Androgen receptor-specific DNA binding to an element in the first exon of the human secretory component gene. Biochemical foumal 353 611-620.

He B \& Wilson EM 2002 The $\mathrm{NH}_{2}$-terminal and carboxyl-terminal interactions in the human androgen receptor. Molecular Genetics and Metabolism 75 293-298.

He B, Lee LW, Minges JT \& Wilson EM 2002 Dependence of selective gene activation on the androgen receptor $\mathrm{NH}_{2}$ - and COOH-terminal interaction. Fournal of Biological Chemistry 277 25631-25639.

Jiricny J \& Corman N 1991 The study of protein-DNA interactions by methylation. In Biomethods, vol 5, pp 121-131. Eds J-P Jost \& H-P Saluz.

Kallio PJ, Palvimo JJ, Mehto M \& Janne OA 1994 Analysis of androgen receptor-DNA interactions with receptor proteins produced in insect cells. Fournal of Biological Chemistry $\mathbf{2 6 9}$ 11514-11522.

Klinge CM, Jernigan SC, Smith SL, Tyulmenkov VV \& Kulakosky PC 2001 Estrogen response element sequence impacts the conformation and transcriptional activity of estrogen receptor $\alpha$. Molecular and Cellular Endocrinology 174 151-166.

Kumar R, Baskakov IV, Srinivasan G, Bolen DW, Lee JC \& Thompson EB 1999 Interdomain signalling in a two-domain fragment of the human glucocorticoid receptor. Fournal of Biological Chemistry 274 24737-24741.

Kumar R, Lee C, Bolen DW \& Thompson EB 2001 The conformation of the glucocorticoid receptor AF-1/taul domain induced by osmolyte binds co-regulatory proteins. Fournal of Biological Chemistry 276 18146-18152.

Kumar R, Betney R, Lee C, Thompson EB \& McEwan IJ 2004 Induced $\alpha$-helix structure in AF-1 of the androgen receptor upon binding transcription factor TFIIF. Biochemistry 276 18146-18152.

Lareyre J-J, Reid K, Nelson C, Kaspar S, Rennie PS, Orgebin-Crist M-C \& Matusik RJ 2000 Characterization of an androgen-specific response region within the $5^{\prime}$ flanking region of the murine epididymal retinoic acid binding protein gene. Biology of Reproduction 63 1881-1892.

Lefsti JA \& Yamamoto K R 1998 Allosteric effects of DNA on transcriptional regulators. Nature 392 885-888.

Liu GZ, Wang H \& Wang Z 2003 Identification of a highly conserved domain in the androgen receptor that suppresses the DNA-binding domain-DNA interactions. Foumal of Biological Chemistry 278 14956-14960. 
Loven MA, Wood JR \& Nardulli AN $2001 a$ Interaction of estrogen receptors $\alpha$ and $\beta$ with estrogen response elements. Molecular and Cellular Endocrinology 181 151-163.

Loven MA, Likhite VS, Choi I \& Nardulli AN $2001 b$ Estrogen response elements alter coactivator recruitment through allosteric modulation of estrogen receptor $\beta$ conformation. Fournal of Biological Chemistry 276 45282-45288.

McEwan IJ 2004 Molecular mechanisms of androgen receptormediated gene regulation: structure-function analysis of the AF-1 domain. Endocrine-Related Cancer 200411 281-293.

Nelson CC, Hendy SC, Shukin RJ, Cheng H, Bruchovsky N, Koop BF \& Rennie PS 1999 Determinants of DNA sequence specificity of the androgen, progesterone, and glucocorticoid receptors: evidence for differential steroid receptor response elements. Molecular Endocrinology 13 2090-2107.

Parker MG, Webb P, Needham M, White R \& Ham J 1987 Identification of androgen response elements in mouse mammary tumour virus and rat prostate C3 gene. Fournal of Cell Biochemistry 35 285-292.

Patel L, Abate C \& Curran T 1990 Altered protein conformation on DNA binding by Fos and Jun. Nature 347 572-575.

Reid KJ, Hendy SC, Saito J, Sorensen P \& Nelson CC 2001 Two classes of androgen receptor elements mediate cooperativity through allosteric interactions. Fournal of Biological Chemistry 276 2943-2952.

Reid J, Kelly SM, Watt K, Price NC \& McEwan IJ 2002 Conformational analysis of the androgen receptor amino-terminal domain involved in transactivation. Fournal of Biological Chemistry 277 20079-20086.

Rennie PS, Bruchovsky N, Leco KJ, Sheppard PC, McQueen SA, Cheng H, Snoek R, Hamel A, Bock ME, MacDonald BS, Nickel BE, Chang C, Liao S, Cattini PA \& Matusik RJ 1993 Characterisation of two cis-acting DNA elements involved in the androgen regulation of the probasin gene. Molecular Endocrinology 7 23-36.

Roche PJ, Hoare SA \& Parker MG 1992 A consensus DNA-binding site for the androgen receptor. Molecular Endocrinology 6 2229-2235.

Rudlett SE \& Miesfeld RL 1995 Quantitative differences in androgen and glucocorticoid receptor DNA binding properties contribute to receptor-selective transcriptional regulation. Molecular and Cellular Endocrinology 109 1-10.

Schoenmakers E, Alen P, Verrijdt G, Peeters B, Verhoeven G, Rombauts W \& Claessens F 1999 Differential DNA binding by the androgen and glucocorticoid receptors involves the second Zn-finger and a C-terminal extension of the DNA-binding domains. Biochemical fournal 341 515-521.

Schoenmakers E, Verrijdt G, Peeters B, Verhoeven G, Rombauts W \& Claessens F 2000 Differences in DNA binding characteristics of the androgen and glucocorticoid receptors can determine hormone-specific responses. Fournal of Biological Chemistry 275 12290-12297.
Shaffer PL, Jivan A, Dollins DE, Claessens F \& Gewirth DT 2004 Structural basis of androgen receptor binding to selective androgen response elements. PNAS 101 4758-4763.

Steketee K, Berrevoets CA, Dubbink HJ, Doesburg P, Hersmus R, Brinkmann AO \& Trapman J 2002 Amino acids 3-13 and amino acids in and flanking the 23 FxxLF27 motif modulate the interaction between the N-terminal and ligand-binding domain of the androgen receptor. European Fournal of Biochemistry $\mathbf{2 6 9}$ 5780-5791.

Takeshita A, Yen PM, Ikeda M, Cardona GR, Liu Y, Koibuchi N, Norwitz ER \& Chin WW 1998 Thyroid hormone response elements differentially modulate the interactions of thyroid hormone receptors with two receptor binding domains in the steroid receptor coactivator-1. Fournal of Biological Chemistry 273 21554-21562.

Traish AM \& Pavao M 1996 Binding of site-directed monoclonal antibodies to an epitope located in the $\mathrm{A} / \mathrm{B}$ region (amino acids 140-154) of human estrogen receptor-induced conformational changes in an epitope in the DNA-binding domain. Steroids 61 $549-556$

Verrijdt G, Schoenmakers E, Haelens A, Peeters B, Verhoeven G, Rombauts W \& Claessens F 2000 Change of specificity mutations in androgen-selective enhancers. Fournal of Biological Chemistry $\mathbf{2 7 5}$ 12298-12305.

Verrijdt G, Schauwaers K, Haelens A, Rombauts W \& Claessens F 2002 Functional interplay between two response elements with distinct binding characteristics dictates androgen specificity of the mouse sex-limited protein enhancer. Fournal of Biological Chemistry 277 35191-35201.

Verrijdt G, Haelens A \& Claessens F 2003 Selective DNA recognition by the androgen receptor as a mechanism for hormone-specific regulation of gene expression. Molecular Genetics and Metabolism 78 175-185.

Wood JR, Greene GL \& Mardulli AN 1998 Estrogen response elements as allosteric modulators of estrogen receptor conformation. Molecular and Cellular Biology 18 1972-1934.

Wood JR, Likhite VS, Loven MA \& Nardulli AN 2001 Allosteric modulation of estrogen receptor conformation by different estrogen response elements. Molecular Endocrinology 15 $1114-1126$.

Zilliacus J, Wright APH, Carlstedt-Duke J \& Gustafsson J-Å 1995 Structural determinants of DNA-binding specificity by steroid receptors. Molecular Endocrinology 9 389-400.

Zhou Z, Corden JL \& Brown T 1997 Identification and characterisation of a novel androgen response element composed of a direct repeat. Fournal of Biological Chemistry 272 8227-8235.

Received 5 January 2005

Accepted 25 January 2005

Made available online as an Accepted Preprint 31 January 2005 